\title{
Vestibular Rehabilitation for the Patients with Intractable Vestibular Neuritis
}

\author{
Hiroaki Ichijo \\ Ichijo Ear, Nose and Throat Clinic, Hirosaki, Japan \\ Email: hiro3387@mvj.biglobe.ne.jp
}

How to cite this paper: Ichijo, H. (2018) Vestibular Rehabilitation for the Patients with Intractable Vestibular Neuritis. International Journal of Otolaryngology and Head \& Neck Surgery, 7, 350-358. https://doi.org/10.4236/ijohns.2018.76035

Received: September 30, 2018

Accepted: November 11, 2018

Published: November 14, 2018

Copyright $\odot 2018$ by author and Scientific Research Publishing Inc. This work is licensed under the Creative Commons Attribution International License (CC BY 4.0).

http://creativecommons.org/licenses/by/4.0/

(c) (i) Open Access

\begin{abstract}
Objective: To clarify whether vestibular rehabilitation is effective in improving spontaneous nystagmus in patients with intractable vestibular neuritis. Methods: The subjects were 8 patients (6 females and 2 males) with vestibular neuritis who revealed long-lasting (more than 2 months since the onset) horizontal spontaneous nystagmus toward the healthy side. We used thumbs-up head shaking for vestibular rehabilitation. This exercise involves active head shaking $(1 \mathrm{~Hz})$ while staring at one's thumb nail. One set is 10 cycles. We asked the patient to do 3 sets (morning, afternoon, and night) every day. Results: The mean value of the slow-phase velocity of spontaneous nystagmus before treatment was $4.1 \%$, and that 3 months after vestibular rehabilitation was $4.1^{\circ}$ s. No improvement was observed. Conclusion: Vestibular rehabilitation is not always effective in improving spontaneous nystagmus in patients with intractable vestibular neuritis. Therefore, clinicians should consider the possibility of long-term incomplete central compensation.
\end{abstract}

\section{Keywords}

Video-Oculography, Caloric Testing, Vestibular Compensation, Benign Paroxysmal Positional Vertigo

\section{Introduction}

The pathophysiology of vestibular neuritis is a sudden interruption of input from the unilateral peripheral vestibular organ, and typical symptoms include severe vertigo, nausea, and vomiting. Usually, symptoms and disequilibrium improve with time due to vestibular compensation. In some cases, ipsilateral vestibular nerve function recovers. If not, the central nervous system restores the imbalance between the right and left vestibular nuclei. This process is a unique function that the auditory system does not have. The duration of symptoms va- 
ries widely; some patients recover within 2 weeks, and severe cases continue presenting with spontaneous nystagmus for more than 1 year [1] [2].

The main treatment is steroids. However, the efficacy of corticosteroids is controversial. Not all patients are cured by steroid therapy. We sometimes experience patients who complain of wobbling while walking despite early treatment with corticosteroids. We call such cases intractable vestibular neuritis. In this study, we diagnosed intractable vestibular neuritis in patients with spontaneous nystagmus for more than 2 months after the onset. The last option for intractable vestibular neuritis is rehabilitation. Although Strupp et al. [3] reported that exercises are effective for early stage vestibular neuritis, there is little information regarding the treatment for chronic vestibular imbalance. The aim of this study was to clarify whether vestibular rehabilitation is effective in improving spontaneous nystagmus in patients with intractable vestibular neuritis.

\section{Materials and Methods}

\subsection{Subjects}

The subjects were 8 patients with intractable vestibular neuritis, who were diagnosed at our institution between May 2014 and October 2017.

Inclusion criteria:

1) Sudden and spontaneous vertigo with nausea and vomiting.

2) Long-lasting (more than 2 months since the onset) horizontal spontaneous nystagmus toward the healthy side.

3) No caloric response on the affected ear, and good caloric response from the intact side.

4) Routine visit for more than 6 months since the onset.

Exclusion criteria:

1) Cochlear symptoms related to vertigo.

2) Central nervous system disorder.

\subsection{Spontaneous Nystagmus}

An indicator of imbalance is the horizontal component of spontaneous nystagmus in a supine position. It was recorded in the dark with the patients' eyes open using an infrared charge-coupled device camera. After performing video-oculography, we measured the slow-phase velocity. Spontaneous nystagmus was recorded at monthly intervals.

\subsection{Caloric Testing}

Over $20 \mathrm{~s}$, we slowly poured $1 \mathrm{ml}$ of iced water $\left(6^{\circ} \mathrm{C}\right)$ into the right external auditory canal in a left-ear-down $90^{\circ}$ position using a small syringe. Each subject was rotated to a supine position. The head of the supine subject was tilted forward by $20^{\circ}$ because the lateral canal forms an angle of $18.8^{\circ}$ (smaller than the conventional measurement) with the Reid horizontal plane [4]. After a 10-min rest, we stimulated the left ear in the same way. The testing was performed in the dark, 
with the patients' eyes open, using an infrared charge-coupled device camera.

\subsection{Calculation of Caloric Response}

When a patient presents with spontaneous nystagmus, a complex calculation needs to be performed. Measurement of the maximum slow-phase velocity is necessary for quantitative assessment. In the following calculation formula, $S$ indicates the slow-phase velocity of the horizontal component of spontaneous nystagmus.

When the affected side is on the left, the direction of spontaneous nystagmus is rightward. The direction of caloric nystagmus of the left ear is the same as that of spontaneous nystagmus because we use iced water stimulation. Hence, the response of the affected side is

$$
L-S
$$

where $L$ is the maximum slow-phase velocity after left ear stimulation. The direction of caloric nystagmus of the right ear is opposite to that of spontaneous nystagmus. Hence, the response of the healthy side is

$$
R+S
$$

where $R$ is the maximum slow-phase velocity after right ear stimulation.

When the affected side is on the right, the direction of spontaneous nystagmus is leftward. The direction of caloric nystagmus of the right ear is the same as that of spontaneous nystagmus. Hence, the response of the affected side is

$$
R-S
$$

where $R$ is the maximum slow-phase velocity after right ear stimulation. The direction of caloric nystagmus of the left ear is opposite to that of spontaneous nystagmus. Hence, the response of the healthy side is

$$
L+S
$$

where $L$ is the maximum slow-phase velocity after left ear stimulation.

\subsection{Video-Oculography}

Nystagmus was recorded and converted to digital data. Two-dimensional video-oculography was performed using Image 1.36 (a public domain, Java-based image processing program developed at the National Institute of Health) and a Macintosh computer (Mac OS 10.6.2). For analysis of the horizontal and vertical components, the XY center of the pupil was calculated [5].

\subsection{Vestibular Rehabilitation}

We used thumbs-up head shaking (Figure 1). This exercise involves active head shaking $(1 \mathrm{~Hz})$ while staring at one's thumb nail. One set is 10 cycles. We asked the patient to do 3 sets (morning, afternoon, and night) everyday.

\subsection{Medication}

Medication during the early stage was not standardized among patients because 
some had been introduced from other hospitals. We prescribed steroids only if the patient visited our institution within 2 weeks of the onset.

\section{Results}

Data on the 8 patients are shown in Table 1.

\subsection{Spontaneous Nystagmus}

Video-oculography results for Patient no. 8 are shown in Figure 2. The slowphase velocity after treatment is almost the same as that before treatment. Figure 3 (boxplot) shows the change in the horizontal component of spontaneous nystagmus in all patients. The mean value of the slow-phase velocity $(n=8)$ before treatment was $4.1^{\circ} \mathrm{s}$, and that 3 months after vestibular rehabilitation was $4.1^{\circ} / \mathrm{s}$. No improvement was observed.

\subsection{Caloric Testing (Unit Is $\%$ s)}

The mean value of the caloric response of the affected side was 0.04 , the minimum value was -1.6 , and the maximum value was 1.5 . We determined that the affected side had no response because \pm 2 is considered to be the error range. The mean value of caloric response of the healthy side was 27.4 , the minimum value was 13.8, and the maximum value was 49 . Figure 4 shows the results for Patient No. 5.

\subsection{Secondary BPPV (Benign Paroxysmal Positional Vertigo)}

Three patients presented with transient vertical/torsional positional nystagmus in Dix-Hallpike testing. The affected sides were the same as the affected sides of the vestibular neuritis. Secondary BPPV occurred 1 - 3 months after the onset. After the Epley maneuver, vertical/torsional positional nystagmus disappeared in 2 patients; however, 1 patient was not cured.

Table 1. Results.

\begin{tabular}{|c|c|c|c|c|c|c|c|c|c|c|c|c|}
\hline \multirow[t]{2}{*}{ Patient } & \multirow[t]{2}{*}{ Age } & \multirow[t]{2}{*}{ Sex } & \multirow[t]{2}{*}{$\begin{array}{l}\text { Affected } \\
\text { side }\end{array}$} & \multirow[t]{2}{*}{ Occupation } & \multirow[t]{2}{*}{$\begin{array}{l}\text { Upper airway } \\
\text { infection }\end{array}$} & \multirow[t]{2}{*}{$\begin{array}{c}\text { Onset } \\
\text { time }\end{array}$} & \multirow[t]{2}{*}{ BPPV } & \multirow[t]{2}{*}{ Corticosteroid } & \multicolumn{2}{|c|}{$\begin{array}{c}\text { Caloric } \\
\text { response }(\% / s)\end{array}$} & \multicolumn{2}{|c|}{$\begin{array}{c}\text { Spontaneous } \\
\text { nystagmus }(\% / s)\end{array}$} \\
\hline & & & & & & & & & $\begin{array}{l}\text { Affected } \\
\text { side }\end{array}$ & $\begin{array}{c}\text { Healthy } \\
\text { side }\end{array}$ & Before & $\begin{array}{c}3 \text { months } \\
\text { after }\end{array}$ \\
\hline 1 & 45 & $\mathrm{~F}$ & $\mathrm{~L}$ & Office worker & - & am 10 & - & + & -1.6 & 24.4 & 3.8 & 4 \\
\hline 2 & 50 & $\mathrm{~F}$ & $\mathrm{~L}$ & Housewife & - & pm 5 & - & - & -1.3 & 24.4 & 3.7 & 3.6 \\
\hline 3 & 61 & $\mathrm{~F}$ & $\mathrm{~L}$ & Careworker & - & pm 5 & - & + & -0.1 & 37.4 & 3.8 & 4.3 \\
\hline 4 & 77 & $\mathrm{~F}$ & $\mathrm{~L}$ & Housewife & - & pm 3 & + & - & 0.8 & 49 & 3.7 & 2.1 \\
\hline 5 & 45 & $\mathrm{~F}$ & $\mathrm{R}$ & Housewife & - & am 10 & + & - & -0.8 & 31 & 7.8 & 6.9 \\
\hline 6 & 54 & $\mathrm{M}$ & $\mathrm{R}$ & Office worker & - & pm 10 & + & - & 0.3 & 19.9 & 5.2 & 7.6 \\
\hline 7 & 67 & $\mathrm{M}$ & $\mathrm{R}$ & Retired & - & pm 2 & - & - & 1.5 & 18.7 & 2.8 & 1.6 \\
\hline 8 & 68 & $\mathrm{~F}$ & $\mathrm{R}$ & Housewife & - & am 8 & - & + & 1.5 & 13.8 & 2 & 2.3 \\
\hline Mean & 58.4 & & & & & & & & 0.04 & 27.4 & 4.1 & 4.1 \\
\hline
\end{tabular}




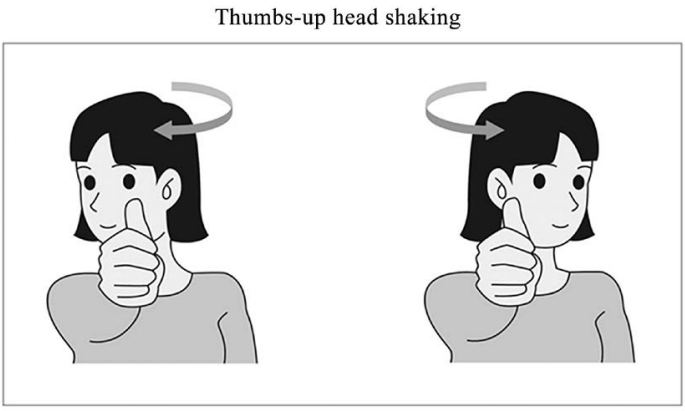

Figure 1. Active head shaking $(1 \mathrm{~Hz})$ while staring at one's thumb nail. One set is 10 cycles. We asked the patient to do 3 sets (morning, afternoon, and night) every day.

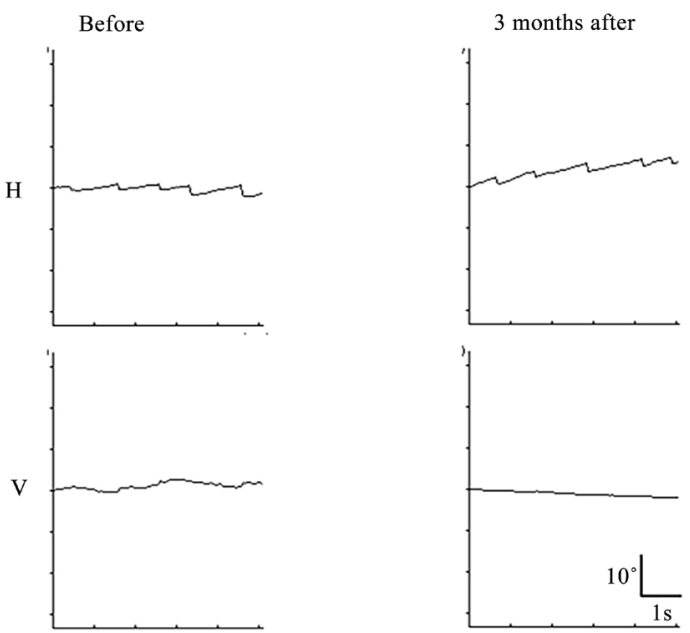

Figure 2. Video-oculography (position trace) of spontaneous nystagmus in Patient no. 8. The slow-phase velocity after treatment was almost the same as that before treatment. The upward deflection in horizontal $(\mathrm{H})$ and vertical $(\mathrm{V})$ eye movements are indicated as being toward the right and upward, respectively.

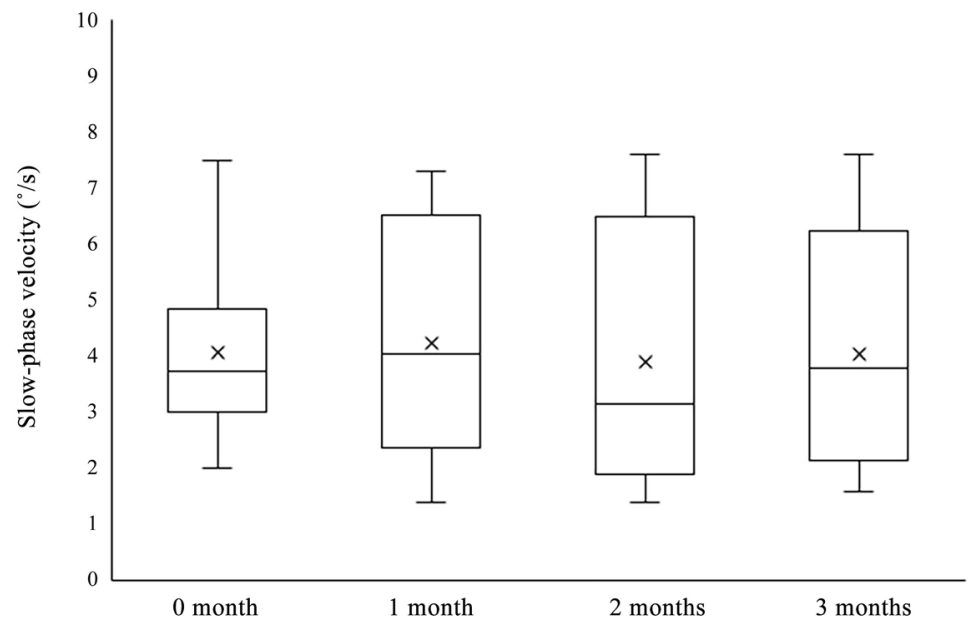

Figure 3. The change in the horizontal component of spontaneous nystagmus in all patients (boxplot). The mean value of the slow-phase velocity of spontaneous nystagmus $(\mathrm{n}=8)$ before treatment was $4.1 \%$, and that 3 months after vestibular rehabilitation was $4.1 \%$. No improvement was observed. 0 month indicates the day prior to vestibular rehabilitation. 


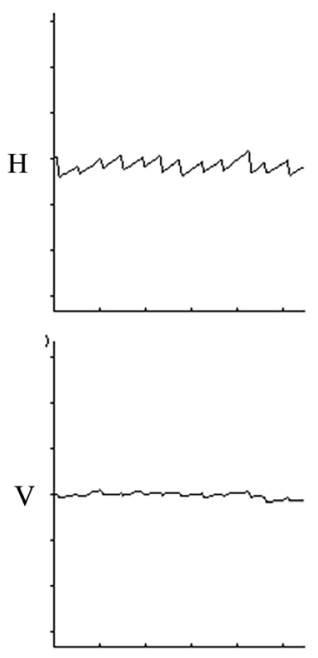

(a)

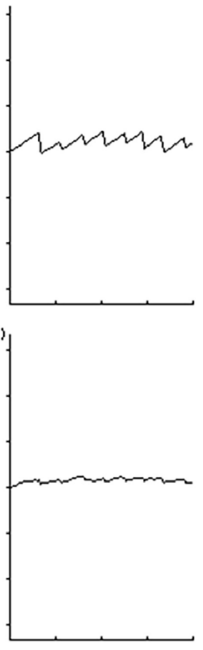

(b)

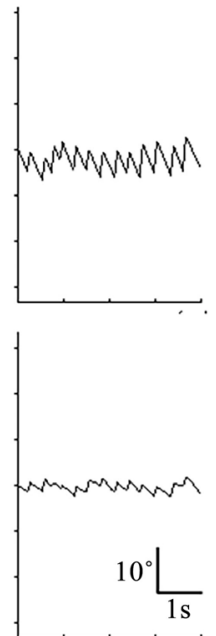

(c)

Figure 4. Video-oculography (position trace) of caloric testing for Patient No. 5. (a) Spontaneous nystagmus; (b) Caloric nystagmus after stimulation of the right ear (no response); (c) Caloric nystagmus after stimulation of the left ear (good response). The upward deflection in horizontal $(\mathrm{H})$ and vertical $(\mathrm{V})$ eye movements are indicated as being toward the right and upward, respectively.

\section{Discussion}

Our results suggest that vestibular rehabilitation is not always effective in improving spontaneous nystagmus in patients with intractable vestibular neuritis. Therefore, treatment cannot always cure the chronic disequilibrium.

In general, when we try to evaluate the efficacy of some treatments, there is a problem of which indicator to use. Although symptoms are important, they have methodological limitations because they are subjective data. Asymmetry of the caloric response is a quantitative indicator; however, it is influenced by spontaneous nystagmus. We need a complex calculation to obtain an accurate result. Measurement of the maximum slow-phase velocity of caloric nystagmus is necessary for quantitative assessment. Although Goudakos et al. [6] reported a change in the extent of canal paresis, the test results were unreliable because they did not take into account the strength of spontaneous nystagmus. Strupp et al. [3] found that vestibular exercises improve central vestibulospinal compensation by comparing the total sway path values.

For quantification of the imbalance between the right and left vestibular nuclei, spontaneous nystagmus is the most useful due to its objectivity and sensitivity. Additionally, it is easy to record and does not burden the patient. Therefore, we adopted the slow-phase velocity of spontaneous nystagmus as an indicator.

If the unilateral vestibular afferent signal is suddenly interrupted, a highly abnormal situation occurs and the person feels a severe spinning sensation. However, symptoms and imbalance gradually improve with time due to the natural healing ability. Hence, it is difficult to evaluate the efficacy of some treatments in an acute stage. If a patient gets better, we cannot judge whether this is due to natural causes or due to the treatment. In order to reduce the influence of the 
natural healing ability, we selected patients with chronic vestibular neuritis. We asked them to perform thumbs-up head shaking every day for 3 months. However, none of the patients showed improvement of spontaneous nystagmus.

Steroids have been widely used as an acute stage treatment. However, the efficacy of corticosteroids is controversial. Several researchers have demonstrated beneficial clinical application of corticosteroids [7] [8]. On the other hand, Yoo et al. [9] reported that there were no significant differences between the control group and the steroid group. It is clear that not all patients are cured by corticosteroid therapy because 3 patients enrolled in the present study did not recover, in spite of early treatment with steroids.

Another treatment is rehabilitation. There are many kinds of vestibular rehabilitation. While it is impossible to do many kinds of exercise everyday, we selected one rehabilitation exercise (thumbs-up head shaking) that the patients could easily perform. However, no patients showed any improvements.

What did we expect from the thumbs-up head shaking? Acceleration (stimulation) to the affected vestibular end organ does not reach the vestibular nucleus. The aim of the thumbs-up head shaking exercise was to increase the input from the healthy inner ear. The vestibulo-ocular reflex acts to maintain a retinal image when a person actively rotates their head while staring at a target. Not only semicircular canals, but also the central nervous system via visual input contribute to this function. Especially, the vestibulo-cerebellum plays an important role. Hence, it is reasonable to try to correct the imbalance by increasing the impulse to the vestibulo-cerebellum. However, the mechanism of vestibular compensation is controversial [10]. It is a complicated process involved in brain-stem reticular formation and proprioceptive information, and it has not been established whether enhancing the action of vestibular input hastens the process of central compensation.

We found that BPPV occurred in 3 patients 1 - 3 months after the onset of vestibular neuritis. There have been many similar reports [11] [12] [13]. This indicates that vestibular neuritis causes BPPV. Regarding the etiology of BPPV, Ichijo proposed a micro-otoconia accumulation theory [14]. If the damage spreads not only to the vestibular nerve, but also to the end organs, it is likely that the otoconia on the utricular macula will detach. If many otoconia gradually aggregate and become a mass, its movement produces cupular bending and causes a spinning sensation and nystagmus. This micro-otoconia accumulation theory can explain the time lag between the onset of vestibular neuritis and that of BPPV. The findings also indicate superior vestibular neuritis. In the 3 patients with BPPV, the disorder was limited in the superior vestibular nerve. Thus, the inferior vestibular nerve was intact. Signals from the posterior semicircular canal enter the vestibular nucleus via the inferior vestibular nerve. In Dix-Hallpike testing, vertical/torsional nystagmus was elicited. This phenomenon indicates that the posterior canal and inferior vestibular nerve are functional. If caloric stimulation reaches the posterior canal, vertical/torsional nystagmus should oc- 
cur after stimulation of the affected side. Indeed, additional nystagmus did not occur (Figure 4). This finding provides evidence that caloric stimulation does not reach the posterior canal. This logic is consistent with the theory that caloric nystagmus is a pure horizontal canal ocular reflex [15].

\section{Conclusion}

Vestibular rehabilitation is not always effective for improving spontaneous nystagmus in patients with intractable vestibular neuritis. Therefore, clinicians should consider the possibility of long-term incomplete central compensation.

\section{Acknowledgements}

We thank Dr. Kazunori Futai for preparing some of the figures.

\section{Declaration of Interest}

The author reports no conflicts of interest. The author alone is responsible for the content and writing of the paper.

\section{References}

[1] Katsarkas, A. and Outerbridge, J.S. (1981) Compensation of Unilateral Vestibular Loss in Vestibular Neuronitis. Annals of the New York Academy of Sciences, 374, 784-793. https://doi.org/10.1111/j.1749-6632.1981.tb30919.x

[2] Ichijo, H., Akita, J., Ishii, K., Miyakoshi, Y., Tominaga, T. and Shinkawa, H. (1996) Follow-Up Study of Vestibular Neuronitis. Nihon Jibiinkoka Gakkai Kaiho, 99, 306-313. https://doi.org/10.3950/jibiinkoka.99.306

[3] Strupp, M., Arbusow, V., Maag, K.P., Gall, C. and Brandt, T. (1998) Vestibular Exercises Improve Central Vestibulospinal Compensation after Vestibular Neuritis. Neurology, 51, 838-844. https://doi.org/10.1212/WNL.51.3.838

[4] Della Santina, C.C., Potyagaylo, V., Migliaccio, A.A., Minor, L.B. and Carey, J.P. (2005) Orientation of Human Semicircular Canals Measured by Three-Dimensional Multiplanar CT Reconstruction. Journal of the Association for Research in Otolaryngology, 6, 191-206. https://doi.org/10.1007/s10162-005-0003-x

[5] Ikeda, T., Hashimoto, M., Horiike, O. and Yamashita, H. (2002) Simple Eye Movement Image Analysis Technique Using NIH Image. Equilibrium Research, 61, 90-96. https://doi.org/10.3757/jser.61.90

[6] Goudakos, J.K., Markou, K.D., Psillas, G., Vital, V. and Tsaligopoulos, M. (2014) Corticosteroids and Vestibular Exercises in Vestibular Neuritis. Single-Blind Randomized Clinical Trial. JAMA Otolaryngol Head Neck Surgery, 140, 434-440. https://doi.org/10.1001/jamaoto.2014.48

[7] Ariyasu, L., Byl, F.M., Sprague, M.S. and Adour, K.K. (1990) The Beneficial Effect of Methylprednisolone in Acute Vestibular Vertigo. Archives of OtolaryngologyHead and Neck Surgery, 116, 700-703. https://doi.org/10.1001/archotol.1990.01870060058010

[8] Karlberg, M.L. and Magnusson, M. (2011) Treatment of Acute Vestibular Neuronitis with Glucocorticoids. Otology \& Neurotology, 32, 1140-1143. https://doi.org/10.1097/MAO.0b013e3182267e24

[9] Yoo, M.H., Yang, C.J., Kim, S.A., Park, M.J., Ahn, J.H., Chung, J.W. and Park, H.J. 
(2017) Efficacy of Steroid Therapy Based on Symptomatic and Functional Improvement in Patients with Vestibular Neuritis: A Prospective Randomized Controlled Trial. European Archives of Oto-Rhino-Laryngology, 274, 2443-2451. https://doi.org/10.1007/s00405-017-4556-1

[10] Curthoys, I.S. and Halmagyi, G.M. (1995) Vestibular Compensation: A Review of the Oculomotor, Neural, and Clinical Consequences of Unilateral Vestibular Loss. Journal of Vestibular Research, 5, 67-107. https://doi.org/10.1016/0957-4271(94)00026-X

[11] Murofushi, T., Halmagyi, G.M., Yavor, R.A. and Colebatch, J.G. (1996) Absent Vestibular Evoked Myogenic Potentials in Vestibular Neurolabyrinthitis. An Indicator of Inferior Vestibular Nerve Involvement? Archives of Otolaryngology-Head and Neck Surgery, 122, 845-848. https://doi.org/10.1001/archotol.1996.01890200035008

[12] Balatsouras, D.G., Koukoutsis, G., Ganelis, P., Economou, N.C., Moukos, A., Aspris, A. and Katotomichelakis, M. (2014) Benign Paroxysmal Positional Vertigo Secondary to Vestibular Neuritis. European Archives of Oto-Rhino-Laryngology, 271, 919-924. https://doi.org/10.1007/s00405-013-2484-2

[13] Mandala, M., Santoro, G.P., Awrey, J. and Nuti, D. (2010) Vestibular Neuritis: Recurrence and Incidence of Secondary Benign Paroxysmal Positional Vertigo. Acta Oto-Laryngologica, 130, 565-567. https://doi.org/10.3109/00016480903311278

[14] Ichijo, H. (2017) Onset Time of Benign Paroxysmal Positional Vertigo. Acta OtoLaryngologica, 137, 144-148. https://doi.org/10.1080/00016489.2016.1221130

[15] Ichijo, H. (2011) Can Caloric Testing Evaluate the Function of Vertical Semicircular Canals? Acta Oto-Laryngologica, 131, 716-721. https://doi.org/10.3109/00016489.2011.554436 